assistance is shown by the fact that of the 287 scholars who have been re-established, 202 are still within the university world. The Council has played an important part in this work, not only within Great Britain by raising during the past year $£ 24,000$ for temporary maintenance grants, but also on an international basis by organising a central information bureau. The Council announces that it hopes to continue its information service as long as possible, although it proposes to end its emergency financial grants by July, 1936. It hopes during the coming year to raise funds to create a limited number of research fellowships to retain in Great Britain the services of some of the most distinguished of the displaced scholars. The need for the continuation of the Council's work is evident. During the past two months, 50 more university teachers have been dismissed in Germany, and, as the report points out, "it is impossible for the exiled scholars to regard return to Germany as a possible alternative to further exile". We hope that the Council will receive sufficient financial support to continue its patient work, for it is making a historic contribution to the cause of free learning. Copies of the report may be obtained free on application to the General Secretary, Academic Assistance Council, Rooms of the Royal Society, Burlington House, London, W.1.

\section{Flight Experiments with Compression-Ignition Engines}

The Air Ministry has ordered a number of "Culverin" 720 horse-power heavy oil engines from Messrs. D. Napier and Son, Ltd. It is understood that these are to be used for complete operational tests in large flying boats. Imperial Airways is also interested in the same problem for civil aircraft, and will doubtless be watching these results. The Napier engine is a horizontal water-cooled engine, built under licence from the German Junkers company. The Bristol Aeroplane Co., Ltd., has also developed a compression-ignition engine of the radial air-cooled type, which has actually gained the world's altitude record for aircraft powered with that type of engine. The Diesel type engine has a definite advantage in long-distance flight owing to its smaller oil consumption, but as it is structurally heavier than the petrol engine this advantage is outweighed on short flights. With modern design and performance of heavier-than-aircraft, there is no gain in using it for a flight of less than about eight hours duration. Another major point in its favour is the lessened risk of fire after a crash. Although the fuel oil used is not non-inflammable, its flash point is much lower than that of petrol, and the risk of ignition from flame or hot parts is less. A minor trouble to be dealt with is the lack of facilities for the distribution of this fuel oil at the present time. The oil distributing companies will need considerable additions to their plant before fuel oil will be available upon as worldwide a scale as is petrol.

\section{Polarising Light Filters}

THe Eastman Kodak Company, at the ninth International Congress of Photography recently held in Paris, demonstrated a new kind of light polariser, known as the 'Pola filter'. This is made in sheets and may be used to produce effects similar to those obtained with a Nicol prism. Thus when used in pairs, any desired degree of extinction may be obtained by rotating one filter in relation to the other. In photography alone there are many very useful applications for these filters, such as the elimination of surface reflections from glass windows, water, coloured objects (with consequent increased saturation of the colours), the modulation of blue sky brightness without alteration of hue, etc. The comparative cheapness of these filters, and the possibility of manufacturing them in large sizes, opens up a great vista of applications, in which has been suggested their use to combat headlight glare with motor-cars.

\section{Prehistoric India}

A DISCovery which, if substantiated, holds out promise of great moment for prehistoric archæology in the Near and Middle East, is announced from India. According to a dispatch from Karachi, which appears in The Times of July 19, remains of a city of an earlier date than Mohenjo-daro have been discovered alongside the bed of the Indus River at a site known as Kol Deja or Narujadaro in Khaipur State, Bombay. The discovery was made by $\mathrm{Mr}$. Utam Thakur, a research scholar, in the course of survey work. It is stated that shell and earthenware bangles, decorated images and decorative pottery were found. If further investigation should afford ground for accepting the claim that this material represents an earlier stage of civilisation than that already known from the Indus valley, where the earliest city at Mohenjo-daro is dated at about 3300 B.c., it will have a crucial bearing on the problem of the relations of the early civilisations of Sumeria and India. The authorities of Khaipur State have taken measures for guarding the site, and $\mathrm{Mr}$. Thakur is now engaged in seeking financial aid for carrying out systematic excavation in the coming season.

\section{Equipment of a Photo-Elastic Laboratory}

A PAPER of the greatest interest to all who contemplate the design and equipment of a photo-elastic laboratory, and indeed of interest to engineers generally, was read to the Junior Institution of Engineers by Prof. E. G. Coker and appears in full, with many illustrations, in the Journal of the Institution of April 1935. It was prepared with the view of giving an outline of the essential requirements of a photo-elastic laboratory when a start is being made from the beginning of things and not merely an adjunct to a larger laboratory already well supplied with much of the experimental apparatus and machinery, which can be utilised for photo-elastic work. For this purpose, the paper opens with a concise statement of the elements of photo-elasticity, a subject which might with advantage be taken up much more widely and at an earlier stage than at present, as the elastic properties of materials are of more or less importance to all engaged in technical 